\title{
Genetic analysis of rennet coagulation time, curd-firming rate, and curd firmness assessed over an extended testing period using mechanical and near-infrared instruments
}

\author{
A. Cecchinato, ${ }^{*}$ C. Cipolat-Gotet, ${ }^{*}$ J. Casellas, $\dagger$ M. Penasa,${ }^{* 1}$ A. Rossoni, $\ddagger$ and G. Bittante ${ }^{*}$ \\ *Department of Agronomy, Food, Natural resources, Animals and Environment (DAFNAE), University of Padova, Viale dell'Università 16, \\ 35020 Legnaro, Italy \\ †Departament de Ciència Animal i dels Aliments, Universitat Autònoma de Barcelona, 08193 Bellaterra, Spain \\ fItalian Brown Swiss Cattle Breeders Association, Loc. Ferlina 204, 37012 Bussolengo, Italy
}

\begin{abstract}
The aims of this study were (1) to analyze rennet coagulation time (RCT), curd-firming rate, and curd firmness obtained by extending the standard 30-min testing time to $45 \mathrm{~min}$; (2) to estimate heritabilities of the aforementioned traits determined by mechanical (Formagraph; Foss Electric, Hillerød, Denmark) and near-infrared optical (Optigraph; Ysebaert, Frépillon, France) instruments, and to assess the statistical relevance of their genetic background by using the Bayes factor procedure, the deviance information criterion, and the mean squared error; (3) to estimate phenotypic and genetic relationships between instruments within trait and between traits within instrument; and (4) to obtain correlations for sire rankings based on the used instruments. Individual milk samples were collected from 913 Brown Swiss cows reared in 63 herds located in Trento Province (Italy). Milk coagulation properties (MCP) were measured using 2 different instruments: Formagraph and Optigraph. Both instruments were housed in the same laboratory and operated by the same technician. Each sample was analyzed simultaneously on each instrument. All experimental conditions (milk temperature and the concentration and type of rennet) were identical. For the analysis, univariate and bivariate animal models were implemented using Bayesian methods. Univariate analyses were conducted to test the hypothesis that the traits showed additive genetic determination. Deviance information criterion, Bayes factor, and mean squared error were used as model choice criteria. The main results were that (1) RCT could be measured on all samples by extending the observation time to $45 \mathrm{~min}$, and its genetic parameters $\left(h^{2}=0.23\right)$ and breeding values could be estimated while avoiding the bias of noncoagulating samples; (2) curd-firming rate could be measured on almost all milk
\end{abstract}

Received May 30, 2012.

Accepted September 24, 2012.

${ }^{1}$ Corresponding author: mauro.penasa@unipd.it samples, and its genetic parameters could be estimated for the first time on a field data set $\left(h^{2}=0.21\right)$; (3) for the first time, genetic parameters of curd firmness 45 min after rennet addition $\left(h^{2}=0.12\right)$ were estimated, and they were compared with curd firmness $30 \mathrm{~min}$ after rennet addition $\left(h^{2}=0.17\right)$; and (4) MCP estimated using the Optigraph appeared to be genetically different from those determined by Formagraph, with the partial exception of RCT (genetic correlation $=0.97$ ). Breeding strategies for the improvement of MCP must be planned with caution. Currently, the high throughput, ease of use, and reduced costs of analysis make predictions obtained from mid-infrared spectroscopy (MIRS) on untreated milk samples a promising alternative to produce relevant data at the population level. The use of mechanical lactodynamographs to establish reference data for MIRS calibrations have been already studied, whereas the use of near-infrared optical lactodynamographs as a reference method for MIRS calibrations needs to be investigated.

Key words: milk coagulation property, mechanical and optical lactodynamograph, heritability, Bayes factor

\section{INTRODUCTION}

Measurement of milk coagulation properties (MCP) is of special relevance for cheese manufacturing. The most used instruments to assess MCP are lactodynamographs (renneting meters) by which rennet coagulation time (RCT, min), curd-firming time $\left(\mathbf{k}_{20}, \min \right)$, and curd firmness are measured after addition of the clotting enzyme to raw milk (Annibaldi et al., 1977; Zannoni and Annibaldi, 1981; McMahon and Brown, 1982). Lactodynamographs record physicochemical changes occurring in milk during the coagulation process when the enzyme hydrolyzes $\kappa$-casein aggregates and induces changes in milk viscosity and elasticity (Auldist et al., 2001; O'Callaghan et al., 2002).

Several systems have been adopted to determine MCP in cow's milk. Traditionally, laboratory mechani- 
cal instruments such as the Formagraph (FRM; Foss Electric, Hillerød, Denmark) and the Computerized Renneting Meter (Polo Trade, Monselice, Italy) have been used, whereas optical instruments based on infrared technologies have been often used to monitor MCP directly in the cheese-making vats (Payne et al., 1993; Laporte et al., 1998; O'Callaghan et al., 2002). Recently, 2 categories of infrared optical instruments have been adopted to predict MCP at laboratory level. The first includes medium infrared spectrometers (MIRS) to predict MCP from raw milk samples analyzed without induction of rennet coagulation (Dal Zotto et al., 2008; De Marchi et al., 2009). The second includes lactodynamographs such as the Optigraph (OPT; Ysebaert, Frépillon, France), which has been proposed to determine MCP through induction of rennet coagulation of milk (Panari et al., 2002; Kübarsepp et al., 2005). The 2 types of lactodynamographs record the same parameters on coagulating samples but using different principles. Mechanical measures are based on continuous recording of the movement, after the immersion of small loop pendulum in linearly oscillating samples of coagulating milk, induced by minute forces applied to the pendulum as a consequence of the milk coagulation (McMahon and Brown, 1982). The optical instrument continuously measures the optical signal in the near-infrared (NIR) region $(820 \mathrm{~nm})$ and estimates the MCP by means of specific calibration equations. Recently, a phenotypic study by Cipolat-Gotet et al. (2012) demonstrated that FRM and OPT yield different results with the partial exception of RCT.

Several studies have been carried out to estimate genetic parameters of MCP measured by mechanical lactodynamographs (e.g., Lindström et al., 1984; Ikonen et al., 2004; Cecchinato et al., 2012), and recently one study dealt with OPT (Vallas et al., 2010). No direct comparisons between genetic parameters of MCP obtained from mechanical and optical instruments are currently available. Moreover, past research on genetic aspects of MCP dealt with renneting parameters determined for 30 min after the addition of the clotting enzyme, and faced the problem of milk samples that do not coagulate within the testing time of $30 \mathrm{~min}$ (the so-called noncoagulating samples, NC) and of the potential bias in the estimation of genetic parameters of MCP and breeding values of animals (Cecchinato and Carnier, 2011). A significant fraction of milk samples do not usually attain curd firmness of $20 \mathrm{~mm}$ within the 30-min testing time; hence, $\mathrm{k}_{20}$ is often excluded from genetic analyses. Only a few studies have estimated genetic parameters for $k_{20}$, and they were based on a small number of cows reared on experimental farms (Tervala et al., 1985; Ikonen et al., 1997).
Therefore, the objectives of this study were (1) to analyze RCT, $\mathrm{k}_{20}$, and curd firmness obtained by extending the standard 30-min testing time $\left(\mathbf{a}_{30}\right)$ to 45 min $\left(\mathbf{a}_{\mathbf{4 5}}\right) ;(2)$ to estimate heritabilities of the aforementioned traits measured by FRM and OPT instruments, and to assess the statistical relevance of their genetic background by using the Bayes factor (BF) procedure, the deviance information criterion (DIC), and the mean squared error (MSE); (3) to estimate phenotypic and genetic relationships between instruments within trait and between traits within instrument; and (4) to obtain correlations for sire rankings based on the instruments used.

\section{MATERIALS AND METHODS}

\section{Field Data}

In total, 913 Brown Swiss cows from 63 herds located in Trento Province (Italy) were sampled once during the evening milking between April 2010 and February 2011. Within a given day, only one herd was sampled. Two milk subsamples per cow were collected and immediately refrigerated at $4^{\circ} \mathrm{C}$ without preservative. One random subsample was transported to the Milk Quality Laboratory of the Breeders Federation of Trento Province (Trento, Italy) for composition analysis. The other subsample was transferred to the cheese-making laboratory of the Department of Agronomy, Food, Natural resources, Animals and Environment (DAFNAE) of the University of Padova (Legnaro, Italy) for MCP analysis. All samples were processed within $20 \mathrm{~h}$ of collection. Information on cows and herds were provided by the Breeders Federation of Trento Province (Italy). Pedigree information was supplied by the Italian Brown Swiss Cattle Breeders Association (ANARB, Verona, Italy) and included cows with phenotypic records for the investigated traits and all their known ancestors.

\section{Analysis of Milk Quality}

Individual milk subsamples were analyzed for fat, protein, and casein contents using MilkoScan FT6000 (Foss). Somatic cell count was obtained from the Fossomatic FC counter (Foss) and was then converted to SCS by means of logarithm transformation (Ali and Shook, 1980). The $\mathrm{pH}$ of the subsamples was measured before MCP analysis, using a Crison Basic 25 electrode (Crison, Barcelona, Spain).

\section{Analysis of Milk Coagulation Properties}

Milk coagulation properties were determined using FRM and OPT. Both instruments were housed in the 
same laboratory and operated by the same technician. Each subsample was analyzed simultaneously on each instrument. All experimental conditions (milk temperature and the concentration and type of rennet) were identical. Two racks containing 10 cuvettes (one rack per instrument) were prepared; milk samples $(10 \mathrm{~mL})$ were heated to $35^{\circ} \mathrm{C}$ and $200 \mu \mathrm{L}$ of rennet solution (Hansen Standard 160, with $80 \pm 5 \%$ chymosin and $20 \pm 5 \%$ pepsin; Pacovis Amrein AG, Bern, Switzerland) diluted to $1.6 \%$ (wt/vol) in distilled water, to yield 0.051 international milk clotting units (IMCU)/ $\mathrm{mL}$, was added to samples after milk heating. Both instruments yield the width $(\mathrm{mm})$ of the oscillatory graph during testing: the OPT records a datum every $6 \mathrm{~s}$ and the FRM every $15 \mathrm{~s}$. The observation period continued for 90 min after rennet addition but, for the purposes of the present work, only the first 45 min were considered. Variations in absorbance, as detected by OPT, were transformed by instrument software using an appropriate calibration equation to mimic the shape of the graph afforded by traditional mechanical instruments (Kübarsepp et al., 2005). This means that MCP can be calculated using either device. The MCP recorded were (1) the time from addition of enzyme to the beginning of visible coagulation (gelification) within a time interval of $45 \mathrm{~min}$ (RCT, min); (2) the interval from gelification (RCT) to the time at which the width of the graph attained $20 \mathrm{~mm}\left(\mathrm{k}_{20}, \mathrm{~min}\right) ;(3)$ the firmness of the curd at 30 min from rennet addition $\left(\mathrm{a}_{30}, \mathrm{~mm}\right)$; and (4) the firmness of the curd at $45 \mathrm{~min}$ from rennet addition $\left(\mathrm{a}_{45}, \mathrm{~mm}\right)$. Samples that did not coagulate within 30 min were classified as NC (Ikonen et al., 1999), although extension of analysis allowed $\mathrm{RCT}$ and $\mathrm{k}_{20}$ to be recorded for all samples.

\section{Statistical Analysis}

Nongenetic Effects. Nongenetic effects to be included in mixed models to estimate genetic parameters for MCP determined by FRM and OPT were identified through preliminary analysis based on the GLM procedure (SAS Inst. Inc., Cary, NC). For all traits, the model accounted for the effects of herd (63 levels), DIM (class 1: $<60 \mathrm{~d}$, class 2: 60-120 d, class 3: 121-180 d, class 4: 181-240 d, class 5: 241-300 d, and class 6: >300 d), parity (1 to 4 or more), and renneting meter sensor (10 levels) of the lactodynamograph, being the pendula of FRM and the monochromators of OPT. All these effects were important sources of variation $(P<0.05)$ except for the renneting meter sensor for RCT and $\mathrm{k}_{20}$.

Univariate Models for Testing the Hypothesis of Additive Genetic Determination. The genetic background of the MCP (y) was investigated by analyzing data under the following hierarchical model:

$$
\mathbf{y}=\mathbf{X} \mathbf{b}+\mathbf{Z}_{1} \mathbf{h}+\mathbf{Z}_{2} \mathbf{a}+\mathbf{e},
$$

where $\mathbf{y}$ was the vector of phenotypic records with dimension $n ; \mathbf{X}, \mathbf{Z}_{1}$, and $\mathbf{Z}_{2}$ were appropriate incidence matrices for systematic effects (b), herd-date effects (h), and polygenic additive genetic effects (a), respectively; and e was the vector of residual effects. Specifically, $\mathbf{b}$ included nongenetic effects of DIM, parity, and renneting meter sensor (only for $\mathrm{a}_{30}$ and $\mathrm{a}_{45}$ ).

All models were analyzed under a standard Bayesian approach. The joint distribution of the parameters in the model was proportional to

$$
\begin{aligned}
& p\left(\mathbf{b}, \mathbf{h}, \mathbf{a}, \sigma_{e}^{2}, \sigma_{h}^{2}, \sigma_{a}^{2} \mid \mathbf{y}\right) \propto p\left(\mathbf{y} \mid \mathbf{b}, \mathbf{h}, \mathbf{a}, \sigma_{e}^{2}\right) p\left(\sigma_{e}^{2}\right) p(\mathbf{b}) \\
& \times p\left(\mathbf{h} \mid \sigma_{h}^{2}\right) p\left(\sigma_{h}^{2}\right) p\left(\mathbf{a} \mid \mathbf{A}, \sigma_{a}^{2}\right) p\left(\sigma_{a}^{2}\right)
\end{aligned}
$$

where A was the numerator relationship matrix between individuals (Wright, 1922), and $\sigma_{e}^{2}, \sigma_{h}^{2}$, and $\sigma_{a}^{2}$ were the residual, herd-date, and additive genetic variances, respectively. The a priori distributions of $\mathbf{h}$ and a were assumed multivariate normal, as follows:

$$
\begin{aligned}
& p\left(\mathbf{h} \mid \sigma_{h}^{2}\right) \sim N\left(0, \mathbf{I} \sigma_{h}^{2}\right) \text { and } \\
& p\left(\mathbf{a} \mid \sigma_{a}^{2}\right) \sim N\left(0, \mathbf{A} \sigma_{a}^{2}\right),
\end{aligned}
$$

where I was an identity matrix with dimensions equal to the number of elements in $\mathbf{h}$. Priors for $\mathbf{b}$ and variance components were assumed to be flat.

The univariate model was used to test for additive genetic determination of each trait. Different criteria were used for this purpose. The DIC (Spiegelhalter et al., 2002) was computed both for the model including the additive genetic effect and for the reduced model without this effect; differences in DIC of more than 7 units were considered important (Spiegelhalter et al., 2002). The BF (Kass and Raftery, 1995; García-Cortés et al., 2001; Casellas et al., 2010) was computed as a pair-wise comparison by calculating the ratio between the posterior probabilities of 2 competing models, taking any positive value between $>0$ and $+\infty$. In this case, a linear mixed model with additive polygenic effects (numerator model) was compared against a model without additive polygenic effects (denominator model), where $>1 \mathrm{BF}$ favored the numerator model and $<1 \mathrm{BF}$ favored the denominator model. In this report, the $\mathrm{BF}$ results were discussed within the context of the Jeffreys (1984) discrete scale of evidences. This scale classifies the BF according to 6 levels of evidence for the numerator model, objectively classifying the $\mathrm{BF}$ as follows: denominator model supported, not worth more than a bare mention, substantial evidence, strong 
evidence, very strong evidence, and decisive evidence. From now on, this terminology will be systematically used when referring to the BF. The MSE between real and predicted phenotypic records was also used to compare models (i.e., the one with additive polygenic effects and the same model without additive polygenic effects). For all MCP traits, the expectation of the predictive distribution of a given record was computed as in Varona et al. (1999):

$$
\hat{y}_{M C P i}=\mathbf{x}_{i} \hat{\beta}+\mathbf{z}_{1 i} \hat{\mathbf{h}}+\mathbf{z}_{2 i} \hat{\mathbf{a}}-\hat{\mathbf{e}}_{i},
$$

where $\hat{y}_{M C P i}$ is the expectation for the $i$ th MCP record, $\mathbf{x}_{i}, \mathbf{z}_{1 i}$, and $\mathbf{z}_{2 i}$ are the $i$ th rows of the incidence matrices that link systematic, herd-date, and additive genetic effects, and $\hat{\mathbf{e}}_{i}$ are the residuals for the $i$ th MCP record. Note that $\hat{\beta}, \mathbf{h}, \hat{\mathbf{a}}$, and $\hat{\mathbf{e}}_{i}$ are posterior median estimates. The MSE was defined as

$$
\mathrm{MSE}=\frac{\sum_{i=n}^{n}\left(y_{i}-\hat{y}_{i}\right)^{2}}{n}
$$

Bivariate Models for Estimating Correlations Between Traits. To estimate genetic correlations between MCP variables, a set of bivariate analyses was conducted, implementing model [1] in its multivariate version. In this case, the involved traits were assumed to jointly follow a multivariate normal (MVN) distribution as well as the additive genetic, herd-date, and residual effects. For these effects, the corresponding prior distributions were

$$
\begin{aligned}
& \mathbf{a} \mid \mathbf{G}_{0}, \mathbf{A} \sim \operatorname{MVN}\left(0, \mathbf{G}_{0} \otimes \mathbf{A}\right), \\
& \mathbf{h} \mid \mathbf{H}_{0} \sim N\left(0, \mathbf{H}_{0} \otimes \mathbf{I}_{n}\right), \\
& \mathbf{e} \mid \mathbf{R}_{0} \sim N\left(0, \mathbf{R}_{0} \otimes \mathbf{I}_{m}\right),
\end{aligned}
$$

where $\mathbf{G}_{0}, \mathbf{H}_{0}$, and $\mathbf{R}_{0}$ were the corresponding variancecovariance matrices between the involved traits, and $\mathbf{a}$, $\mathbf{h}$, and $\mathbf{e}$ were vectors of dimension equal to the number of animals in the pedigree $(n$ and $m$ ) times the number of traits considered.

Gibbs Sampler. Marginal posterior distributions of unknown parameters were estimated by performing numerical integration using the Gibbs sampler (Gelfand and Smith, 1990). This was used to obtain auto-correlated samples from the joint posterior distributions and subsequently from the marginal posterior distributions of all unknowns in the model. The lengths of the chain and the burn-in period were assessed by visual inspection of trace plots, as well as by the diagnostic tests of Geweke (1992) and Gelman and Rubin (1992). After a preliminary run, we decided to construct a single chain consisting of 850,000 iterations and to discard the first 50,000 iterations as a very conservative burnin. Subsequently, 1 of every 200 successive samples was retained, to store draws that were more loosely correlated. Thus, 4,000 samples were used to determine posterior distributions of unknown parameters. The lower and upper bounds of the highest 95\% probability density regions (HPD95\%) for parameters of concern were obtained from the estimated marginal densities. The posterior median was used as the point estimate for all parameters. Auto-correlations between samples and estimates of Monte Carlo standard error (Geyer, 1992) were calculated.

Heritability was computed as follows:

$$
h^{2}=\frac{\sigma_{A}^{2}}{\sigma_{A}^{2}+\sigma_{H}^{2}+\sigma_{E}^{2}},
$$

where $\sigma_{A}^{2}, \sigma_{H}^{2}$, and $\sigma_{E}^{2}$ are additive genetic, herd-date, and residual variances, respectively.

Additive genetic correlations $\left(r_{A}\right)$ were estimated as

$$
r_{A}=\frac{\sigma_{A 1, A 2}}{\sigma_{A 1} \cdot \sigma_{A 2}}
$$

where $\sigma_{A 1, A 2}$ is the additive genetic covariance between trait 1 and 2, and $\sigma_{A 1}$ and $\sigma_{A 2}$ are the additive genetic standard deviations for traits 1 and 2, respectively.

\section{RESULTS}

\section{Milk Coagulation Properties and Phenotypic Variation}

Descriptive statistics for MCP from FRM and OPT are summarized in Table 1. A comprehensive discussion on the phenotypic pattern of milk coagulation and curd firming from mechanical and NIR instruments has been reported by Cipolat-Gotet et al. (2012). In general, the average RCT from OPT was slightly shorter $(1 \mathrm{~min})$ than the value from FRM. Despite this, $\mathrm{a}_{30}$ was approximately $3 \mathrm{~mm}$ smaller when assessed by OPT than by FRM. Curd-firming time was notably longer when evaluated by OPT ( $8.16 \mathrm{~min})$ than by FRM (5.36 min). Finally, $\mathrm{a}_{45}$ was about $8 \mathrm{~mm}$ greater when assessed by OPT $(41.49 \mathrm{~mm})$ than by FRM $(33.65 \mathrm{~mm})$. Rennet coagulation time and $\mathrm{a}_{30}$ from OPT were less variable than the corresponding MCP from FRM, whereas the opposite was found for $\mathrm{a}_{45}$. Variances of MCP from FRM and OPT were statistically different according to Levene's test $(P<0.05$; data not shown $)$ with the 
Table 1. Descriptive statistics $(\mathrm{n}=913)$ of milk coagulation properties assessed using Formagraph (Foss Electric, Hillerød, Denmark) and Optigraph (Ysebaert, Frépillon, France) instruments ${ }^{1}$

\begin{tabular}{|c|c|c|c|c|c|c|c|c|}
\hline \multirow[b]{2}{*}{ Trait $^{2}$} & \multicolumn{4}{|c|}{ Formagraph } & \multicolumn{4}{|c|}{ Optigraph } \\
\hline & Mean & $\mathrm{SD}$ & $\mathrm{P} 1$ & P99 & Mean & $\mathrm{SD}$ & $\mathrm{P} 1$ & P99 \\
\hline $\mathrm{k}_{20}(\min )$ & 5.36 & 3.12 & 1.45 & 17.30 & 8.16 & 2.97 & 3.70 & 17.80 \\
\hline $\mathrm{a}_{30}(\mathrm{~mm})$ & 30.09 & 11.34 & 0.40 & 51.04 & 27.23 & 10.80 & 2.35 & 55.79 \\
\hline $\mathrm{a}_{45}(\mathrm{~mm})$ & 33.66 & 8.43 & 9.03 & 52.20 & 41.49 & 11.54 & 11.87 & 70.62 \\
\hline
\end{tabular}

${ }^{1} \mathrm{P} 1=1$ st percentile; $\mathrm{P} 99=99$ th percentile.

${ }^{2} \mathrm{RCT}=$ rennet coagulation time of samples coagulating within $45 \mathrm{~min}$ from enzyme addition; $\mathrm{k}_{20}=$ curd-firming time of samples reaching 20 $\mathrm{mm}$ of firmness within $45 \mathrm{~min}$ from enzyme addition; $\mathrm{a}_{30}=$ curd firmness at 30 min after enzyme addition; $\mathrm{a}_{45}=$ curd firmness at 45 min after enzyme addition.

exception of $\mathrm{k}_{20}$. In fact, despite mean values being notably different between instruments, $\mathrm{k}_{20}$ values exhibited similar standard deviations. Consequently, the proportion of NC samples at $30 \mathrm{~min}$ (samples without a detectable $\mathrm{a}_{30}$ ) was $6.57 \%$ for FRM and $2.08 \%$ for OPT $(P<0.05$; data not shown). The extension of MCP analysis up to $45 \mathrm{~min}$ allowed the RCT recording for all samples and $\mathrm{k}_{20}$ recording for most late-coagulating milks. The late-coagulating milks also affected the distribution of $\mathrm{a}_{30}$ and $\mathrm{k}_{20}$, whereas $\mathrm{a}_{45}$ showed close to Gaussian distribution.

\section{Heritability of Milk Coagulation Properties}

Point estimates (median of the marginal posterior density of the parameter) for the additive genetic, herddate, and residual variances, and heritabilities of MCP measured by FRM and OPT are shown in Table 2, and the estimated posterior densities of the heritabilities are depicted in Figure 1. All Monte Carlo standard errors were very small, and a lack of convergence was not detected by the Geweke test (data not shown; Geweke, 1992). Marginal posterior distributions were approximately normal; thus, mode, mean, and median were similar, and only the posterior median is reported.

Rennet coagulation time was moderately heritable, and estimates were very similar between instruments (0.230 and 0.241 for FRM and OPT, respectively) with HPD95\% between 0.10 and 0.40 both for FRM and OPT. The posterior densities were symmetric either for FRM and OPT and their shape was similar and almost overlapping. Even though heritability estimates were similar, the additive genetic, herd-date, and residual variances were $41.4,51.1$, and $43.5 \%$ lower when $\mathrm{RCT}$ was determined by OPT than by FRM.

Posterior density distribution and point estimates of heritability for $\mathrm{k}_{20}$ yielded by FRM were very close to those obtained for RCT, whereas the corresponding features from OPT data were much different. Heritability of $\mathrm{k}_{20}$ from OPT was almost twice the value found for the corresponding MCP of FRM and of RCT of both instruments. Moreover, the posterior densities (Figure 1) of the heritability for $\mathrm{k}_{20}$ obtained using OPT were more dispersed (HPD95\% between 0.15 and 0.61 ) than those obtained by FRM, indicating more uncertainty in the estimation of this parameter. The high value of heritability was the consequence of the notably higher additive genetic and lower residual variance of OPT compared with FRM $(+48.8 \%$ and $-33.4 \%$, respectively; Table 2). Estimates of variance due to herd-date effects on this MCP were also higher for OPT than for FRM $(+26.9 \%)$.

Point estimates of heritability for $\mathrm{a}_{30}$ were slightly lower than those estimated for RCT and were comparable between instruments ( 0.171 for FRM and 0.205 for OPT; Table 2 and Figure 1). In addition, the HPD95\% were similar between instruments, varying from 0.04 to 0.40 . Estimates of additive genetic and residual variance were not very different between instruments $(+13.2 \%$ and $-14.3 \%$, respectively), whereas herd-date variance was much higher $(+64.1 \%)$ for OPT than for FRM.

Results for $\mathrm{a}_{45}$ were extremely variable and inconsistent between instruments. Point estimate of additive genetic variance from OPT was almost 5 times that from FRM. This explains the large differences in heritability for $\mathrm{a}_{45}$ assessed by FRM (0.120) and OPT (0.309), also in terms of variation of the point estimate (HPD95\% from 0.02 to 0.27 for FRM, and 0.13 to 0.51 for OPT) as clearly depicted in Figure 1. Even in this case, estimates of heritability for $\mathrm{a}_{45}$ obtained using OPT were characterized by more uncertainty.

The inclusion of the additive polygenic effect improved the goodness of fit of the model for all MCP, regardless of the instrument used to assess MCP (Table 3). In particular, DIC and MSE decreased when the additive polygenic effect was accounted for in the analysis, suggesting a better fitting. The decrease in DIC ranged between 60 and 144 units. The BF confirmed the relevance of including the polygenic effect in the model, particularly in the analysis of $\mathrm{RCT}$, and of $\mathrm{a}_{30}$ 
Table 2. Features of marginal posterior densities of heritability $\left(h^{2}\right)$, additive genetic $\left(\sigma_{a}^{2}\right)$, herd/date $\left(\sigma_{h}^{2}\right)$, and residual variances $\left(\sigma_{e}^{2}\right)$ of milk coagulation properties assessed using Formagraph (Foss Electric, Hillerød, Denmark) and Optigraph (Ysebaert, Frépillon, France) instruments

\begin{tabular}{|c|c|c|c|c|c|}
\hline \multirow[b]{2}{*}{ Trait $^{1} /$ parameter } & \multicolumn{2}{|c|}{ Formagraph } & \multicolumn{2}{|c|}{ Optigraph } & \multirow[b]{2}{*}{$\Delta \%^{4}$} \\
\hline & Median $^{2}$ & HPD $95 \%^{3}$ & Median & HPD95\% & \\
\hline \multicolumn{6}{|l|}{ RCT (min) } \\
\hline$\sigma_{a}^{2}$ & 7.09 & $3.12 ; 13.02$ & 4.16 & $2.01 ; 7.32$ & -41.4 \\
\hline$\sigma_{h}^{2}$ & 4.34 & $2.52 ; 7.41$ & 2.12 & $1.17 ; 3.63$ & -51.1 \\
\hline$\sigma_{e}^{2}$ & 19.44 & $14.46 ; 23.65$ & 11.00 & $8.37 ; 13.29$ & -43.5 \\
\hline$h^{2}$ & 0.230 & $0.10 ; 0.41$ & 0.241 & $0.12 ; 0.41$ & +4.8 \\
\hline \multicolumn{6}{|l|}{$\mathrm{k}_{20}(\min )$} \\
\hline$\sigma_{a}^{2}$ & 2.10 & $0.74 ; 4.33$ & 3.13 & $1.29 ; 5.52$ & +48.8 \\
\hline$\sigma_{h}^{2}$ & 0.29 & $2.52 ; 7.40$ & 0.36 & $0.07 ; 0.82$ & +26.9 \\
\hline$\sigma_{e}^{2}$ & 7.54 & $5.73 ; 9.06$ & 5.02 & $3.12 ; 6.71$ & -33.4 \\
\hline$h^{2}$ & 0.212 & $0.07 ; 0.41$ & 0.368 & $0.15 ; 0.61$ & +73.6 \\
\hline \multicolumn{6}{|l|}{$\mathrm{a}_{30}(\mathrm{~mm})$} \\
\hline$\sigma_{a}^{2}$ & 21.03 & $5.01 ; 46.23$ & 23.82 & $5.94 ; 49.52$ & +13.2 \\
\hline$\sigma_{h}^{2}$ & 6.42 & $1.85 ; 13.57$ & 10.54 & $5.08 ; 19.44$ & +64.1 \\
\hline$\sigma_{e}^{2}$ & 95.33 & $74.01 ; 114.2$ & 81.67 & $61.01 ; 100.3$ & -14.3 \\
\hline$h^{2}$ & 0.171 & $0.04 ; 0.36$ & 0.205 & $0.05 ; 0.40$ & +19.9 \\
\hline \multicolumn{6}{|l|}{$\mathrm{a}_{45}(\mathrm{~mm})$} \\
\hline$\sigma_{a}^{2}$ & 8.37 & $1.74 ; 19.84$ & 38.11 & $16.36 ; 67.22$ & +355.4 \\
\hline$\sigma_{h}^{2}$ & 12.54 & $7.78 ; 20.02$ & 9.80 & $4.57 ; 18.32$ & -21.9 \\
\hline$\sigma_{e}^{2}$ & 49.0 & $39.38 ; 57.34$ & 75.34 & $52.33 ; 96.87$ & +53.9 \\
\hline$h^{2}$ & 0.120 & $0.02 ; 0.27$ & 0.309 & $0.13 ; 0.51$ & +157.5 \\
\hline
\end{tabular}

${ }^{1} \mathrm{RCT}=$ rennet coagulation time of samples coagulating within 45 min from enzyme addition; $\mathrm{k}_{20}=$ curdfirming time of samples reaching $20 \mathrm{~mm}$ of firmness within $45 \mathrm{~min}$ from enzyme addition; $\mathrm{a}_{30}=$ curd firmness at $30 \mathrm{~min}$ after enzyme addition; $\mathrm{a}_{45}=$ curd firmness at $45 \mathrm{~min}$ after enzyme addition.

${ }^{2}$ Median $=$ median of the marginal posterior density of the parameter.

${ }^{3} \mathrm{HPD} 95 \%$ = lower and upper bounds of the $95 \%$ highest posterior density.

${ }^{4}$ Median of the marginal posterior density of the difference between variance components and heritabilities for milk coagulation properties assessed using Formagraph and Optigraph.

and $\mathrm{a}_{45}$ assessed using OPT. The BF between models with and without a genetic component, in fact, gave values $>1$ for all traits, providing evidence that the model was preferable when additive polygenic effects were included. The BF >100 indicated "decisive evidence" of genetic determinism for RCT yielded by both lactodynamographs, and for $\mathrm{a}_{30}$ and $\mathrm{a}_{45}$ obtained with OPT.

\section{Relationships Among Milk Coagulation Properties}

Point estimates (posterior medians) and HPD95\% for genetic $\left(\boldsymbol{r}_{g}\right)$ and phenotypic $\left(\boldsymbol{r}_{p}\right)$ correlations between the same MCP trait assessed using FRM and OPT are reported in Table 4 . The estimated phenotypic correlations were moderate to high and ranged from 0.426 $\left(\mathrm{a}_{45}\right)$ to $0.806(\mathrm{RCT})$. The estimated genetic relationships were always high and were between $0.764\left(\mathrm{k}_{20}\right)$ and 0.974 (RCT).
Within instrument, the phenotypic correlations between the MCP were moderate to high, with some differences between the 2 instruments (Table 5). Genetic correlations between traditional MCP (RCT, $\mathrm{k}_{20}$, and $\mathrm{a}_{30}$ ) were very high, with the only exception being the relationship between RCT and $\mathrm{k}_{20}$ yielded by OPT (0.415). Curd firmness measured at $45 \mathrm{~min}$ from rennet addition yielded very low (and opposite in sign) genetic correlations with RCT with both instruments. The correlations of $\mathrm{a}_{45}$ with $\mathrm{k}_{20}$ and $\mathrm{a}_{30}$ were both low in the case of FRM and very high in the case of OPT.

\section{Relationships Between Sire Rankings}

The relationships between sire rankings based on EBV for each MCP measured using FRM and OPT are depicted in Figure 2. The sire ranking for RCT was only marginally affected by the instrument used to assess the trait, as the correlation between EBV based 
a)

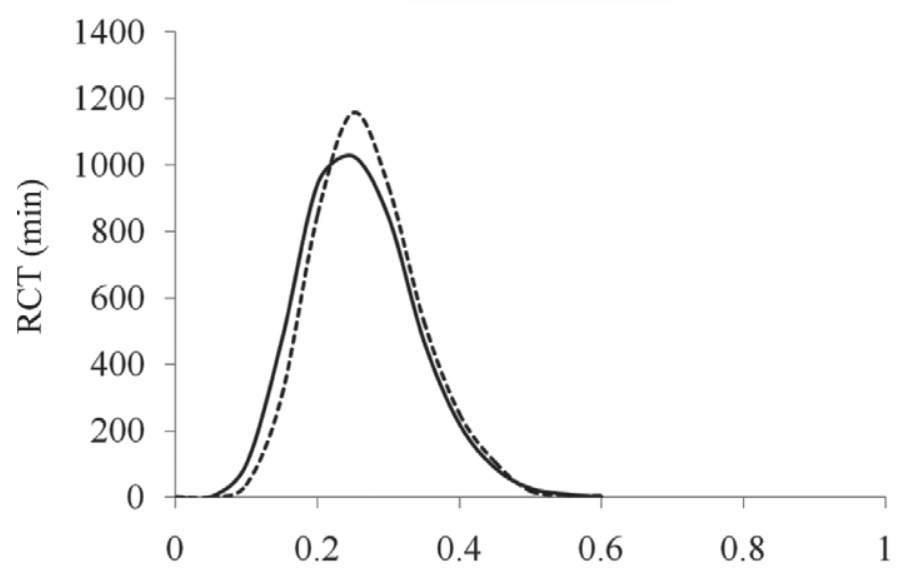

b)

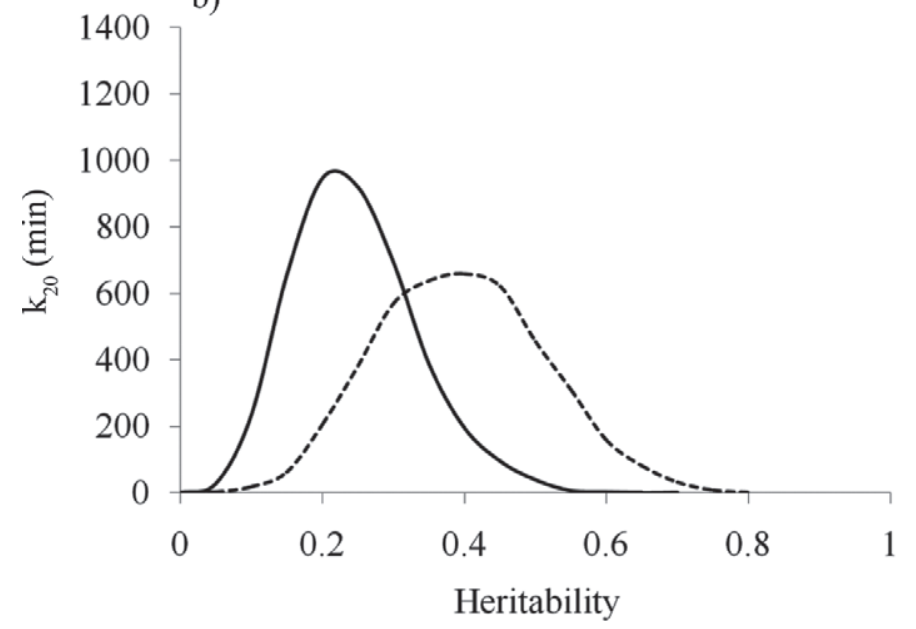

c)

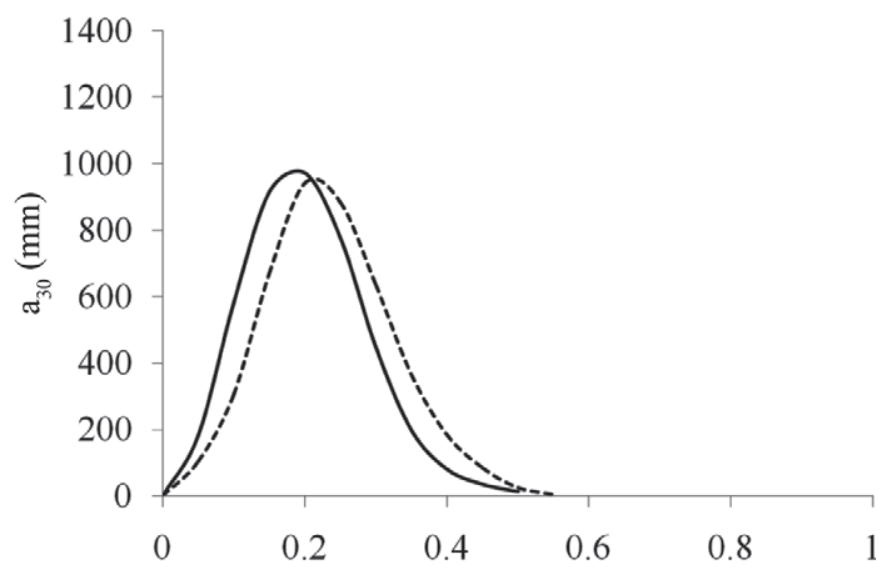

d)

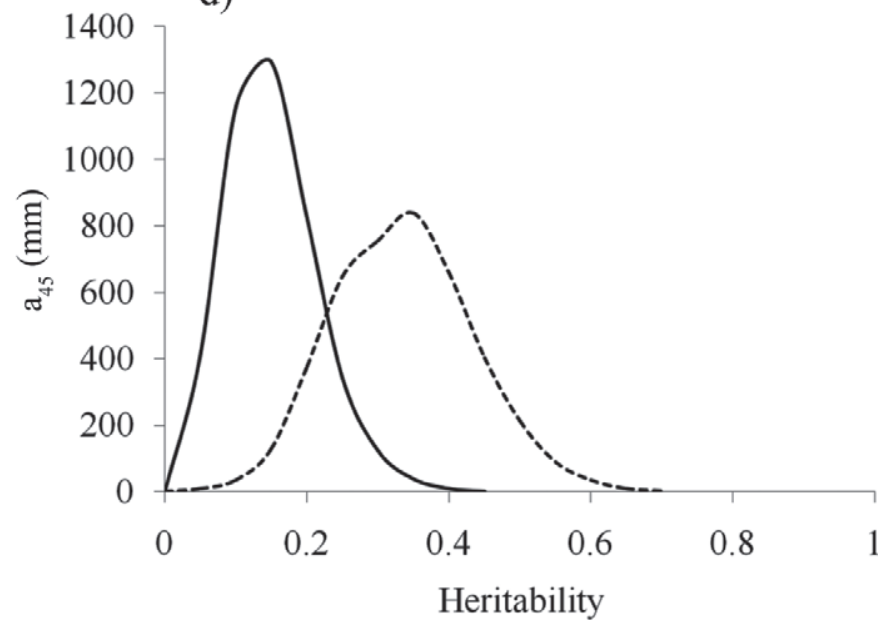

Figure 1. Marginal posterior distributions of the heritability for measures of rennet coagulation time of samples coagulating within 45 min from rennet addition (RCT, min), curd-firming time measured within 45 min from rennet addition ( $\mathrm{k}_{20}$, min), curd firmness at 30 min after rennet addition $\left(\mathrm{a}_{30}, \mathrm{~mm}\right)$, and curd firmness at $45 \mathrm{~min}$ after rennet addition $\left(\mathrm{a}_{45}, \mathrm{~mm}\right)$ assessed using Formagraph (FRM; Foss Electric, Hillerød, Denmark) and Optigraph (OPT; Ysebaert, Frépillon, France) instruments.

on measures of RCT determined by the 2 instruments was 0.99. For $\mathrm{a}_{30}(\mathrm{r}=0.95), \mathrm{a}_{45}(\mathrm{r}=0.94)$, and $\mathrm{k}_{20}(\mathrm{r}=$ $0.87)$, reranking was more pronounced.

\section{DISCUSSION}

\section{Heritability of RCT Measured over an Extended Testing Period}

To our knowledge, this is the first study dealing with estimation of genetic parameters of MCP obtained on a testing period extended to $45 \mathrm{~min}$ to avoid $\mathrm{NC}$ and to allow calculation of $\mathrm{k}_{20}$ on almost all milk samples. Most estimates of genetic parameters for RCT found in the literature have been obtained after discarding NC samples. As the risk of NC milk is higher for cows and progeny characterized by a slow coagulation process, it is clear that both genetic parameters and EBV for RCT can be biased. This risk is particularly high for breeds characterized by slowly coagulating milk, such as Holstein-Friesian and some Scandinavian breeds (Ikonen et al., 1997; Tyrisevä et al., 2004; De Marchi et al., 2007).

To account for the NC samples, Cecchinato and Carnier (2011) compared different statistical models (linear, right-censored linear, survival, and threshold) and concluded that the best approach is to treat $\mathrm{NC}$ samples as censored records. They used individual RCT data from 1,025 Holstein-Friesian cows determined through a 30-min testing-period analysis and found that both additive genetic and error variances estimated using a right-censored linear model were approximately twice 
Table 3. Deviance information criterion (DIC), mean squared error (MSE), and Bayes factor ${ }^{1}$ (BF) for analysis of milk coagulation properties under the model with $(\mathrm{M}+)$ and without $(\mathrm{M}-)$ additive polygenic effects ${ }^{2}$

\begin{tabular}{|c|c|c|c|c|}
\hline \multirow[b]{2}{*}{ Item $^{3}$} & \multicolumn{2}{|c|}{ Formagraph } & \multicolumn{2}{|c|}{ Optigraph } \\
\hline & $\mathrm{M}+$ & M- & $\mathrm{M}+$ & $\mathrm{M}-$ \\
\hline \multicolumn{5}{|c|}{ RCT (min) } \\
\hline DIC & $5,403.7$ & $5,479.5$ & $4,901.5$ & $4,986.3$ \\
\hline MSE & 13.7 & 24.4 & 7.7 & 14.1 \\
\hline $\mathrm{BF}$ & \multicolumn{2}{|c|}{239.8} & \multicolumn{2}{|c|}{$12,193.2$} \\
\hline \multicolumn{5}{|l|}{$\mathrm{k}_{20}(\min )$} \\
\hline DIC & $4,512.5$ & $4,565.3$ & $4,258.1$ & $4,402.4$ \\
\hline MSE & 5.6 & 9.1 & 3.1 & 7.4 \\
\hline $\mathrm{BF}$ & \multicolumn{2}{|c|}{11.9} & \multicolumn{2}{|c|}{${ }^{J .1} 4.8$} \\
\hline \multicolumn{5}{|l|}{$\mathrm{a}_{30}(\mathrm{~mm})$} \\
\hline DIC & $6,796.2$ & $6,841.7$ & $6,670.9$ & $6,730.9$ \\
\hline MSE & 70.3 & 102.1 & 58.7 & 94.1 \\
\hline $\mathrm{BF}$ & \multicolumn{2}{|c|}{15.8} & \multicolumn{2}{|c|}{214.6} \\
\hline \multicolumn{5}{|l|}{$\mathrm{a}_{45}(\mathrm{~mm})$} \\
\hline DIC & $6,161.2$ & $6,189.6$ & $6,655.8$ & $6,767.4$ \\
\hline MSE & 38.64 & 52.2 & 49.1 & 102.7 \\
\hline $\mathrm{BF}$ & \multicolumn{2}{|c|}{3.75} & \multicolumn{2}{|c|}{494.4} \\
\hline
\end{tabular}

${ }^{1}$ Bayes factor of the model with additive polygenic effects against the same model without additive polygenic effects following García-Cortés et al. (2001).

${ }^{2}$ Formagraph from Foss Electric (Hillerød, Denmark); Optigraph from Ysebaert (Frépillon, France).

${ }^{3} \mathrm{RCT}=$ rennet coagulation time of samples coagulating within $45 \mathrm{~min}$ from enzyme addition; $\mathrm{k}_{20}=$ curd-firming time of samples reaching 20 mm of firmness within 45 min from enzyme addition; $\mathrm{a}_{30}=$ curd firmness at $30 \mathrm{~min}$ after enzyme addition; $\mathrm{a}_{45}=$ curd firmness at $45 \mathrm{~min}$ after enzyme addition.

the values found when ignoring $\mathrm{NC}$ samples and using a linear model. Consequently, the heritability estimates were very similar.

Cecchinato et al. (2011) applied a right-censored linear model to RCT data from Brown Swiss cows and compared the results with findings from a previous study that was based on the same data but that ignored NC samples and used a linear instead of a censoredlinear model to analyze the records (Cecchinato et al., 2009). The use of the right-censored linear model led to an increase in the additive genetic variance (4.96 to $5.39 \mathrm{~min}^{2}$ ) and to a even more pronounced increase of the residual variance, so that heritability estimate decreased from 0.34 (Cecchinato et al., 2009) to 0.24 (Cecchinato et al., 2011).

Milk from Holstein-Friesian is usually characterized by a slower coagulation process than milk from Brown Swiss cows, even if the incidence of $\mathrm{NC}$ samples is seldom reported in literature (Malacarne et al., 2005, 2006). It is worth mentioning here that milk protein genetic variants play an important role in explaining the additive genetic variance of MCP (Penasa et al., 2010 ) and that this effect, and consequently the differences among breeds, depends on the relative frequencies of the genetic variants, especially those relative to $\kappa$-casein alleles (Ikonen et al., 1999; Auldist et al., 2002; Bittante et al., 2012). A summary of literature on the effects of genetic variants of milk protein fractions on MCP has recently been reviewed by Bittante et al. (2012), whereas an extensive discussion on the role of $\kappa$-casein gene allelic variants on MCP has been reported by Bonfatti et al. (2010).

In the present study, extending the observation period to $45 \mathrm{~min}$ allowed us to obtain RCT values for all samples, even if $6.67 \%$ of milks coagulated after 30 min from rennet addition. As expected, the estimate of genetic variance of RCT measured by FRM for 45 min $\left(7.09 \mathrm{~min}^{2}\right)$ was higher than those $\left(4.40-5.48 \mathrm{~min}^{2}\right)$ obtained from a linear model on different subsamples of the same breed, but determined for 30 min (Cecchinato et al., 2009). Moreover, the estimate of the additive genetic variance was higher than that previously reported by Cecchinato et al. (2011) on the same breed using the right-censored linear model. A possible explanation is that the distribution of RCT of the entire population measured extending the observation period is not perfectly Gaussian, showing a skewness due to a largerthan-expected right tail. As a result, the assumption of normality of the right-censored linear model can lead to underestimation of the contribution of both additive genetic and residual variances induced by slowly coagulating samples. The heritability estimate of RCT

Table 4. Additive genetic $\left(r_{g}\right)$ and phenotypic $\left(r_{p}\right)$ correlations within milk coagulation properties assessed using Formagraph (Foss Electric, Hillerød, Denmark) and Optigraph (Ysebaert, Frépillon, France) instruments ${ }^{1}$

\begin{tabular}{lccccc}
\hline & \multicolumn{3}{c}{$r_{g}$} & & \multicolumn{3}{c}{$r_{p}$} \\
\cline { 2 - 3 } \cline { 5 - 6 } Trait $^{2}$ & Median & HPD95\% & & Median & HPD95\% \\
\hline RCT (min) & 0.974 & $0.90 ; 0.99$ & & 0.806 & $0.78 ; 0.83$ \\
$\mathrm{k}_{20}(\min )$ & 0.764 & $0.31 ; 0.99$ & & 0.518 & $0.46 ; 0.57$ \\
$\mathrm{a}_{30}(\mathrm{~mm})$ & 0.917 & $0.61 ; 0.99$ & & 0.731 & $0.69 ; 0.76$ \\
$\mathrm{a}_{45}(\mathrm{~mm})$ & 0.847 & $0.45 ; 0.99$ & & 0.426 & $0.36 ; 0.49$ \\
\hline
\end{tabular}

${ }^{1}$ Median = median of the marginal posterior density of the parameter; HPD95\% = lower and upper bounds of the $95 \%$ highest posterior density.

${ }^{2} \mathrm{RCT}=$ rennet coagulation time of samples coagulating within 45 min from enzyme addition; $\mathrm{k}_{20}=$ curdfirming time of samples reaching $20 \mathrm{~mm}$ of firmness within $45 \mathrm{~min}$ from enzyme addition; $\mathrm{a}_{30}=$ curd firmness at 30 min after enzyme addition; $\mathrm{a}_{45}=$ curd firmness at 45 min after enzyme addition. 
Table 5. Additive genetic $\left(r_{g}\right)$ and phenotypic $\left(r_{p}\right)$ correlations between milk coagulation properties within instrument ${ }^{1}$ [Formagraph (Foss Electric, Hillerød, Denmark) or Optigraph (Ysebaert, Frépillon, France)]

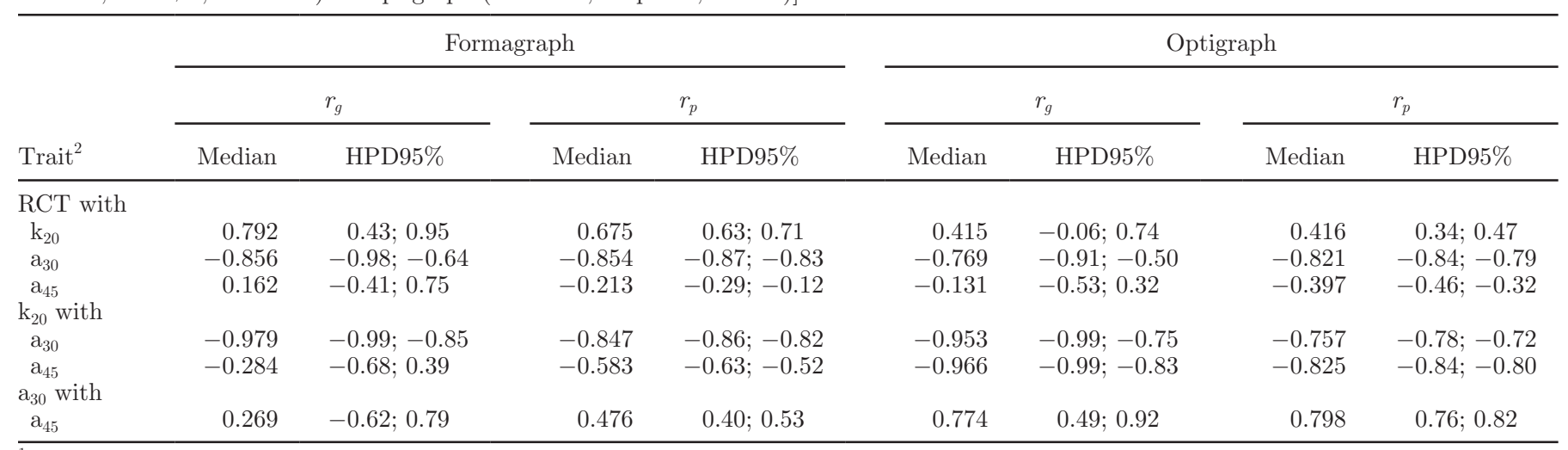

${ }^{1}$ Median = median of the marginal posterior density of the parameter; HPD95\% = lower and upper bounds of the $95 \%$ highest posterior density. ${ }^{2} \mathrm{RCT}=$ rennet coagulation time of samples coagulating within 45 min from enzyme addition; $\mathrm{k}_{20}=$ curd-firming time of samples reaching 20 $\mathrm{mm}$ of firmness within $45 \mathrm{~min}$ from enzyme addition; $\mathrm{a}_{30}=$ curd firmness at 30 min after enzyme addition; $\mathrm{a}_{45}=$ curd firmness at 45 min after enzyme addition.

determined for 45 min was very similar to the estimate found by Cecchinato et al. (2011) from RCT measured for $30 \mathrm{~min}$ and with $\mathrm{NC}$ samples treated as censored.

\section{Genetic Parameters of Curd-Firming Time}

Curd-firming time is valuable at the industry level because it defines the optimal moment for curd cutting, limiting the fines losses with early cutting and the excess moisture of the curd with late cutting (Janhøj and Qvist, 2010). Only 2 studies estimated heritability for $\mathrm{k}_{20}$ : Tervala et al. (1985) reported very low heritability (0.021) using 319 milk samples from Finnish Ayrshire, Finnish Friesian, and Finncattle cows reared in an experimental farm and sampled once, whereas Ikonen et al. (1997) found very high estimates using 174 samples from 59 Finnish Ayrshire (0.540) and 155 samples from 55 Finnish Friesian (0.660) cows, again from an experimental farm.

No estimates are available on field data primarily because not only NC samples but also many slowly coagulating samples do not reach curd firmness of $20 \mathrm{~mm}$ within the usual testing time of $30 \mathrm{~min}$, so that large biases can be expected from both genetic parameters and EBV.

Heritability of $\mathrm{k}_{20}$ from FRM (0.212; Table 2) was close to the average heritability of the other MCP and was intermediate between findings from Tervala et al. (1985) and Ikonen et al. (1997). Tervala et al. (1985) defined $\mathrm{k}_{20}$ differently from our research and from Ikonen et al. (1997). Moreover, the data used by Ikonen et al. (1997) were measured on samples reaching the target value $(20 \mathrm{~mm})$ within $30 \mathrm{~min}$ from gelification, whereas the time limit was $45 \mathrm{~min}$ in the present study. Differences in type and activity of coagulant and in statistical analysis were also found in the studies, making difficult the comparison among them.

No estimates of genetic correlations between $k_{20}$ and other MCP or milk production or composition traits are available in the literature. In the present study, $k_{20}$ showed high positive phenotypic and genetic correlations with RCT and very high negative correlations with $\mathrm{a}_{30}$, confirming that late-coagulating samples are characterized by slow firming rate and low $\mathrm{a}_{30}$. With a genetic correlation of $-0.979, \mathrm{k}_{20}$ seems to add no valuable information, from a genetic point of view, beyond that yielded by $\mathrm{a}_{30}$.

\section{Genetic Parameters of Curd Firmness Evaluated 30 Minutes After Rennet Addition}

In addition to RCT, $\mathrm{a}_{30}$ is also affected by the problem of NC samples. Samples that do not coagulate within 30 min from coagulant addition do not have a curd firmness value over the baseline, which is assumed to be zero. Most published studies report estimates of genetic parameters for $\mathrm{a}_{30}$ that were obtained without the inclusion of NC samples. On the contrary, Ikonen et al. (1999) and Tyrisevä et al. (2004) reported estimates of genetic parameters that were obtained with the inclusion of NC samples. Again, Ikonen et al. (2004) faced this problem comparing 2 approaches. The first was based on the inclusion of $\mathrm{NC}$ samples attributing to $\mathrm{a}_{30}$ a zero value; results showed a higher heritability estimate compared with that found using only coagulated samples (from 0.22 to 0.39 , respectively). The second approach treated $\mathrm{a}_{30}$ as a binary trait (occurrence of coagulation); heritability (0.26) was higher than that obtained excluding $\mathrm{NC}$ samples but much lower than that found including them as zero values. 

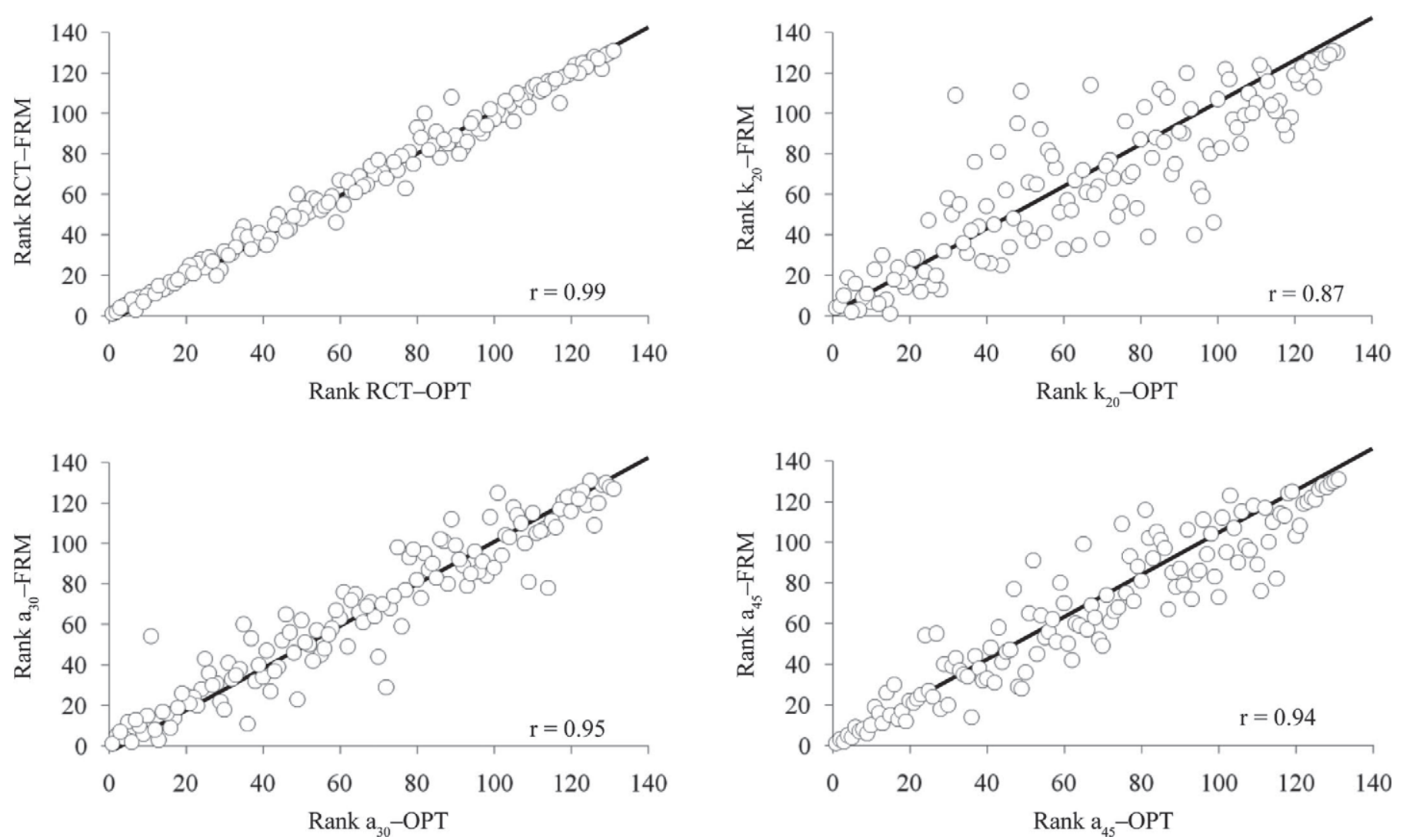

Figure 2. Relationships between sire rankings based on EBV for measures of rennet coagulation time of samples coagulating within 45 min from rennet addition (RCT, min), curd-firming time measured within 45 min from rennet addition $\left(\mathrm{k}_{20}\right.$, min), curd firmness at 30 min after rennet addition $\left(\mathrm{a}_{30}, \mathrm{~mm}\right)$, and curd firmness at 45 min after rennet addition $\left(\mathrm{a}_{45}, \mathrm{~mm}\right)$ assessed using Formagraph (FRM; Foss Electric, Hillerød, Denmark) and Optigraph (OPT; Ysebaert, Frépillon, France) instruments.

The inclusion of samples coagulating after $30 \mathrm{~min}$ (with a zero value) led to an estimate of additive genetic variance slightly larger than that found in the same breed by Cecchinato et al. (2009, 2011) excluding NC samples, but the estimate of the residual variance was even larger so that heritability estimate was relatively low (0.171), similar to the value found by Cassandro et al. (2008) in Holstein-Friesians but lower than the estimates of previous studies in the same breed (Oloffs et al., 1992; Ikonen et al., 1997) and other northern breeds (Tervala et al., 1985; Oloffs et al., 1992; Tyrisevä et al., 2004).

Moreover, despite the different definition of RCT and the use of the zero $\mathrm{a}_{30}$ for $\mathrm{NC}$ samples, the present work confirmed the very high genetic and phenotypic correlations between the $2 \mathrm{MCP}$ traits found in most previous studies. It is clear that the longer the RCT, the shorter the time available for curd firming and the smaller the curd firmness measured at a fixed time, thus confirming the poor informative value of $\mathrm{a}_{30}$ beyond RCT information and the need for new modeling of the curd-firming process and traits that are less interdependent (Bittante, 2011).

\section{Genetic Parameters of Curd Firmness Evaluated 45 Minutes After Rennet Addition}

To overcome the problem of NC samples and define more independent traits, some researchers have extended the interval between enzyme addition and curd firmness measurement to $45 \mathrm{~min}$ (Mariani et al., 1997; Cecchi and Leotta, 2002) or 60 min (O'Brien et al., 2002; Auldist et al., 2004), but no estimates of genetic parameters for $\mathrm{a}_{45}$ or $\mathrm{a}_{60}$ are available in the literature.

The $\mathrm{a}_{45}$ measured by the mechanical instrument is more independent than $\mathrm{a}_{30}$ from the other MCP (RCT and $\mathrm{k}_{20}$ ), both at the phenotypic and genetic levels. Moreover, the correlations between curd firmness measured 30 and $45 \mathrm{~min}$ after rennet addition are relatively low, at both the genetic $(+0.269)$ and phenotypic $(+0.476)$ levels. This low dependence from other traditional MCP is probably because curd firmness tends to increase after gelification to a maximum value and later tends to decrease due to syneresis. The time at which maximum curd firmness is reached can differ greatly in different samples (Bittante et al., 2012), so that $\mathrm{a}_{45}$ can be measured in the ascending or descending phase 
of the curd-firmness curve. Consequently, the same $\mathrm{a}_{45}$ value can be observed in very late coagulating samples as in very early coagulating samples (characterized by rapid syneresis). Because of these considerations, $a_{45}$ does not seem very useful at the industry level, but more research on this topic is needed.

\section{Heritability of MCP Measured by NIR Lactodynamograph}

In previous research (Cipolat-Gotet et al., 2012), MCP determined by mechanical and NIR lactodynamographs on the same samples, in the same laboratory, and by the same technician, have been shown to be different traits, with the partial exception of RCT. Differences were observed in mean values (especially for $\mathrm{k}_{20}$ ), variability (with the exception of $\mathrm{k}_{20}$ ), distribution of the data, and correlations with other MCP and with milk yield and composition traits.

The present study highlighted that the optical device yields MCP that are different from the mechanical device, from the genetic point of view (Table 2). It is worth noting that the NIR lactodynamograph does not measure curd firmness; rather, it predicts curd firmness based on an optical signal that is modified by chemical changes that happen mainly during the first phase of coagulation process (before gelification), not during the second phase, when the physical properties (firmness) change dramatically (O'Callaghan et al., 2002). Thus, the ability of OPT to mimic mechanical instruments is expected to decrease after gelation.

Vallas et al. (2010) found heritability of 0.28 for log-transformed RCT and 0.41 for $\mathrm{a}_{30}$ in Estonian Holstein-Friesian cows. Comparison with the present study is not very useful because the Estonian study used a microbial enzyme (instead of calf rennet) at a very high activity level. As expected, within $30 \mathrm{~min}$ of coagulant addition, Vallas et al. (2010) obtained very short RCT but $\mathrm{a}_{30}$ similar to that found in the present research using a much lower enzyme activity. The use of a high concentration of enzyme is not advisable at the industry level because extra enzyme would reduce cheese yield, change the balance between coagulation time and acidification, and increase the production of bitter peptides beyond the capacity of the enzymes of the cheese microflora to degrade them (Law, 2010). This is particularly true for the production of Protected Designation of Origin cheeses, where production processes cannot be altered to address milk defects and, thus, such cheese-makers require (and pay for) milk of high technological quality (Bertoni et al., 2005; Bittante et al., 2011a,b).

It is worth noting that optical measurements have been used without inducing and monitoring rennet coagulation of milk samples, by predicting MCP on the basis of the MIRS spectra of fresh milk samples through a proper calibration with MCP measured with mechanical lactodynamographs (Dal Zotto et al., 2008; De Marchi et al., 2009). Cecchinato et al. (2009), comparing the genetic parameters of MCP measured by a mechanical lactodynamograph with those of MCP predicted by MIRS spectra, found results similar to those obtained from the present study, with a slight increase of heritability for $\mathrm{RCT}$ and a more pronounced increase of heritability for $\mathrm{a}_{30}$.

\section{Relationships Between MCP Measured by Mechanical and Optical Lactodynamographs}

The genetic correlations between FRM and OPT for the same MCP were much higher than the corresponding phenotypic relationships (Table 4). A similar result was obtained by Cecchinato et al. (2009) for both RCT and $\mathrm{a}_{30}$ predicted by MIRS or measured by mechanical lactodynamograph.

The genetic correlation between RCT yielded by FRM and OPT was very high (0.974), as was the rank correlation of EBV of sires, and the genetic correlation is only slightly higher than that found in the same breed by Cecchinato et al. (2009), who compared measured and MIRS-predicted RCT (0.93, average of 4 subsets). We can assume that the use of MIRS prediction on fresh noncoagulated milk samples is almost as efficient as, but much less expensive and time consuming than, NIR lactodynamograph estimates in a breeding program aimed at improving RCT as an alternative to the use of traditional mechanical lactodynamographs. The genetic correlation between $\mathrm{a}_{30}$ from FRM and OPT (0.917) was lower than the corresponding value exhibited by RCT on the same instrument (0.974), but much higher than the genetic correlation between measured and MIRS predicted $\mathrm{a}_{30}$ obtained by Cecchinato et al. (2009). The genetic correlations between $\mathrm{k}_{20}$ and $\mathrm{a}_{45}$ from FRM and OPT are lower than for RCT and $\mathrm{a}_{30}$ (Table 4 ), but no studies are currently available in literature for comparison.

The genetic correlation between RCT and $\mathrm{a}_{30}$ yielded by OPT was slightly lower than that obtained by FRM ( -0.769 vs. -0.856 , respectively), but indeed very high and much different from the genetic correlation $(-0.160)$ estimated by Vallas et al. (2010) comparing log-transformed RCT and $\mathrm{a}_{30}$ obtained by OPT. No literature comparisons are possible for the other MCP.

\section{CONCLUSIONS}

Extending the standard 30-min testing time to 45 min allowed us to measure RCT of all milk samples 
and $\mathrm{k}_{20}$ for most late-coagulating milks, avoiding $\mathrm{NC}$ records. The use of all RCT data (included those larger than $30 \mathrm{~min}$ ) led to higher additive genetic and residual variances compared with those found in literature, but the heritability remained almost unchanged. For FRM, heritability of $\mathrm{k}_{20}$ was similar to that of RCT, but the genetic correlations with both RCT and $\mathrm{a}_{30}$ were very high, so that the value of $\mathrm{k}_{20}$ for breeding purposes, beyond RCT, is questionable. The relevance of $\mathrm{a}_{30}$ is also questionable because of the high genetic correlation with RCT. Genetic parameters for $\mathrm{a}_{45}$ have been estimated for the first time; this trait exhibited a lower correlation coefficient with RCT than $\mathrm{a}_{30}$, but compared with $\mathrm{a}_{30}$ it was characterized by lower heritability (only for FRM). The MCP estimated by OPT appeared to be different traits from those measured by FRM with the exception of RCT. Breeding strategies for the enhancement of MCP must be planned with caution. Presently, the high throughput, ease of use, and reduced costs of analysis make predictions obtained from MIRS on untreated milk samples a promising alternative for the generation of relevant data at the population level. The use of mechanical lactodynamographs to establish the reference data for MIRS calibrations have been already studied (De Marchi et al., 2009), whereas the use of NIR optical lactodynamographs as reference method for MIRS calibrations needs to be investigated.

\section{ACKNOWLEDGMENTS}

The authors thank Trento Province (Italy) for financial support, the Italian Brown Swiss Cattle Breeders Association (ANARB, Verona, Italy) for supplying pedigree information, and the Superbrown Consortium of Bolzano and Trento for technical support.

\section{REFERENCES}

Ali, A. K. A., and G. E. Shook. 1980. An optimum transformation for somatic cell concentration in milk. J. Dairy Sci. 63:487-490.

Annibaldi, S., G. Ferri, and R. Mora. 1977. Nuovi orientamenti nella valutazione tecnica del latte: Tipizzazione lattodinamografica. Sci. Tecn. Latt. Cas. 28:115-126.

Auldist, M. J., K. A. Johnston, N. J. White, W. P. Fitzsimons, and M. J. Boland. 2004. A comparison of the composition, coagulation characteristics and cheesemaking capacity of milk from Friesian and Jersey dairy cows. J. Dairy Res. 71:51-57.

Auldist, M. J., C. Mullins, B. O'Brien, and T. Guinee. 2001. A comparison of the Formagraph and low amplitude strain oscillation rheometry as methods for assessing the rennet coagulation properties of bovine milk. Milchwissenschaft 56:89-92.

Auldist, M. J., C. Mullins, B. O'Brien, B. T. O'Kennedy, and T. Guinee. 2002. Effect of cow breed on milk coagulation properties. Milchwissenschaft 57:140-143.

Bertoni, G., L. Calamari, M. G. Maianti, and B. Battistotti. 2005. Milk for Protected Denomination of Origin (PDO) cheeses: I. The main required features. Pages 217-228 in Indicators of Milk and Beef Quality. J. F. Hocquette and S. Gigli, ed. EAAP publication
112. Wageningen Academic Publishers, Wageningen, the Netherlands.

Bittante, G. 2011. Modeling rennet coagulation time and curd firmness of milk. J. Dairy Sci. 94:5821-5832.

Bittante, G., A. Cecchinato, N. Cologna, M. Penasa, F. Tiezzi, and M. De Marchi. 2011a. Factors affecting the incidence of first-quality wheels of Trentingrana cheese. J. Dairy Sci. 94:3700-3707.

Bittante, G., N. Cologna, A. Cecchinato, M. De Marchi, M. Penasa, F. Tiezzi, I. Endrizzi, and F. Gasperi. 2011b. Monitoring of sensory attributes used in the quality payment system of Trentingrana cheese. J. Dairy Sci. 94:5699-5709.

Bittante, G., M. Penasa, and A. Cecchinato. 2012. Invited review: Genetics and modeling of milk coagulation properties. J. Dairy Sci. 95:6843-6870. http://dx.doi.org/10.3168/jds.2012-5507.

Bonfatti, V., G. Di Martino, A. Cecchinato, L. Degano, and P. Carnier. 2010. Effects of $\beta$ - $\kappa$-casein (CSN2-CSN3) haplotypes, $\beta$-lactoglobulin (BLG) genotypes, and detailed protein composition on coagulation properties of individual milk of Simmental cows. J. Dairy Sci. 93:3809-3817.

Casellas, J., J. L. Noguera, J. Reixach, I. Díaz, M. Amills, and R. Quintamilla. 2010. Bayes factor analyses of heritability for serum and muscle lipid traits in Duroc pigs. J. Anim. Sci. 88:2246-2254.

Cassandro, M., A. Comin, M. Ojala, R. Dal Zotto, M. De Marchi, L. Gallo, P. Carnier, and G. Bittante. 2008. Genetic parameters of milk coagulation properties and their relationships with milk yield and quality traits in Italian Holstein cows. J. Dairy Sci. 91:371-376.

Cecchi, F., and R. Leotta. 2002. Relazioni tra composizione chimica e parametri lattodinamografici del latte di differenti tipi genetici di bovini. Ann. Fac. Med. Vet. Univ. Pisa 55:223-231.

Cecchinato, A., and P. Carnier. 2011. Short communication: Statistical models for the analysis of coagulation traits using coagulating and non-coagulating milk information. J. Dairy Sci. 94:4214-4219.

Cecchinato, A., M. De Marchi, L. Gallo, G. Bittante, and P. Carnier. 2009. Mid-infrared spectroscopy predictions as indicator traits in breeding programs for enhanced coagulation properties of milk. J. Dairy Sci. 92:5304-5313.

Cecchinato, A., M. Penasa, M. De Marchi, L. Gallo, G. Bittante, and P. Carnier. 2011. Genetic parameters of coagulation properties, milk yield, quality, and acidity estimated using coagulating and noncoagulating milk information in Brown Swiss and HolsteinFriesian cows. J. Dairy Sci. 94:4205-4213.

Cecchinato, A., C. Ribeca, A. Maurmayr, M. Penasa, M. De Marchi, N. P. P. Macciotta, M. Mele, P. Secchiari, G. Pagnacco, and G. Bittante. 2012. Short communication: Effects of $\beta$-lactoglobulin, stearoyl-coenzyme A desaturase 1, and sterol regulatory element binding protein gene allelic variants on milk production, composition, acidity, and coagulation properties of Brown Swiss cows. J. Dairy Sci. 95:450-454.

Cipolat-Gotet, C., A. Cecchinato, M. De Marchi, M. Penasa, and G. Bittante. 2012. Comparison between mechanical and near-infrared methods for assessing coagulation properties of bovine milk. J. Dairy Sci. 95:6806-6819. http://dx.doi.org/10.3168/jds.20125551.

Dal Zotto, R., M. De Marchi, A. Cecchinato, M. Penasa, M. Cassandro, P. Carnier, L. Gallo, and G. Bittante. 2008. Reproducibility and repeatability of measures of milk coagulation properties and predictive ability of mid-infrared reflectance spectroscopy. J. Dairy Sci. 91:4103-4112.

De Marchi, M., R. Dal Zotto, M. Cassandro, and G. Bittante. 2007. Milk coagulation ability of five dairy cattle breeds. J. Dairy Sci. 90:3986-3992.

De Marchi, M., C. C. Fagan, C. P. O'Donnell, A. Cecchinato, R. Dal Zotto, M. Cassandro, M. Penasa, and G. Bittante. 2009. Prediction of coagulation properties, titratable acidity, and $\mathrm{pH}$ of bovine milk using mid-infrared spectroscopy. J. Dairy Sci. 92:423-432.

García-Cortés, L. A., C. Cabrillo, C. Moreno, and L. Varona. 2001. Hypothesis testing for the genetic background of quantitative traits. Genet. Sel. Evol. 33:3-16.

Gelfand, A., and A. F. M. Smith. 1990. Sampling based approaches to calculating marginal densities. J. Am. Stat. Assoc. 85:398-409. 
Gelman, A., and D. B. Rubin. 1992. Inference from iterative simulation using multiple sequences. Stat. Sci. 7:457-511.

Geweke, J. 1992. Evaluating the accuracy of sampling-based approaches to the calculation of posterior moments (with discussion). Pages 164-193 in Bayesian Statistics. J. O. Berger, J. M. Bernardo, A. P. Dawid, and A. F. M. Smith, ed. Oxford University Press, Oxford, UK.

Geyer, C. J. 1992. Practical Markov chain Monte Carlo. Stat. Sci. $7: 473-483$.

Ikonen, T., K. Ahlfors, R. Kempe, M. Ojala, and O. Ruottinen. 1999. Genetic parameters for the milk coagulation properties and prevalence of noncoagulating milk in Finnish dairy cows. J. Dairy Sci. $82: 205-214$.

Ikonen, T., S. Morri, A.-M. Tyrisevä, O. Ruottinen, and M. Ojala 2004. Genetic and phenotypic correlations between milk coagulation properties, milk production traits, somatic cell count, casein content, and $\mathrm{pH}$ of milk. J. Dairy Sci. 87:458-467.

Ikonen, T., M. Ojala, and E.-L. Syväoja. 1997. Effects of composite casein and $\beta$-lactoglobulin genotypes on renneting properties and composition of bovine milk by assuming an animal model. Agric. Food Sci. Finl. 6:283-294.

Janhøj, T., and K. B. Qvist. 2010. Chapter 4: The Formation of Cheese Curd. In Technology of Cheesemaking. 2nd ed. B. A. Law and A. Y. Tamime, ed. Wiley-Blackwell, Oxford, UK. 10.1002/9781444323740.ch4.

Jeffreys, H. 1984. Theory of Probability. 3rd ed. Clarendon Press, Oxford, UK.

Kass, R. E., and A. E. Raftery. 1995. Bayes factors. J. Am. Stat. Assoc. 90:773-795.

Kübarsepp, I., M. Henno, O. Kärt, and T. Tupasela. 2005. A comparison of the methods for determination of the rennet coagulation properties of milk. Acta Agric. Scand. A Anim. Sci. 55:145-148.

Laporte, M. F., R. Martel, and P. Paquin. 1998. The near-infrared optic probe for monitoring rennet coagulation in cow's milk. Int. Dairy J. 8:659-666.

Law, B. A. 2010. Chapter 7: Cheese-ripening and cheese flavour technology. In Technology of Cheesemaking. 2nd ed. B. A. Law and A. Y. Tamime, ed. Wiley-Blackwell, Oxford, UK. 10.1002/9781444323740.ch7.

Lindström, U. B., V. Antila, and J. Syväjärvi. 1984. A note on some genetic and non-genetic factors affecting clotting time of Ayrshire milk. Acta Agric. Scand. 34:349-355.

Malacarne, M., S. Fieni, F. Tosi, P. Franceschi, P. Formaggioni, and A. Summer. 2005. Seasonal variations of the rennet-coagulation properties of herd milks in Parmigiano-Reggiano cheese manufacture: comparison between Italian Friesian and Italian Brown cattle breeds. Ital. J. Anim. Sci. 4(Suppl. 2):242-244.

Malacarne, M., A. Summer, E. Fossa, P. Formaggioni, P. Franceschi, M. Pecorari, and P. Mariani. 2006. Composition, coagulation prop- erties and Parmigiano-Reggiano cheese yield of Italian Brown and Italian Friesian herd milks. J. Dairy Res. 73:171-177.

Mariani, P., P. Serventi, and E. Fossa. 1997. Contenuto di caseina, varianti genetiche ed attitudine tecnologico casearia del latte delle vacche di razza Bruna nella produzione del formaggio grana. Allegato a La Razza Bruna Italiana 2:8-14.

McMahon, D. J., and R. J. Brown. 1982. Evaluation of Formagraph for comparing rennet solutions. J. Dairy Sci. 65:1639-1642.

O'Brien, B., G. Ryan, W. J. Meaney, D. Mcdonagh, and A. Kelly 2002. Effect of frequency of milking on yield, composition and processing quality of milk. J. Dairy Res. 69:367-374.

O'Callaghan, D. J., C. P. O'Donnell, and F. A. Payne. 2002. Review of systems for monitoring curd setting during cheesemaking. Int. J. Dairy Technol. 55:65-74.

Oloffs, K., H. Schulte-Coerne, K. Pabst, and H. O. Gravert. 1992. Die Bedeutung der Proteinvarianten für genetische Unterschiede in der Käsereitauglichkeit der Milch. Zuchtungskunde 64:20-26.

Panari, G., S. Filippi, and G. Lampis. 2002. L'uso dell'optigraph nella determinazione del titolo del caglio di vitello. Sci. Tecn. Latt. Cas. 53:25-32.

Payne, F. A., C. L. Hicks, and P.-S. Shen. 1993. Predicting optimal cutting time of coagulating milk using diffuse reflectance. J. Dairy Sci. 76:48-61.

Penasa, M., M. Cassandro, D. Pretto, M. De Marchi, A. Comin, S. Chessa, R. Dal Zotto, and G. Bittante. 2010. Short communication: Influence of composite casein genotypes on additive genetic variation of milk production traits and coagulation properties in Holstein-Friesian cows. J. Dairy Sci. 93:3346-3349.

Spiegelhalter, D. J., N. G. Best, B. R. Carlin, and A. van der Linde. 2002. Bayesian measures of model complexity and fit. J. R. Stat. Soc. B Methods 64:583-616.

Tervala, H.-L., V. Antila, and J. Syväjärvi. 1985. Factors affecting the renneting properties of milk. Meijeritieteellinen Aikakauskirja XLIII:16-25.

Tyrisevä, A.-M., T. Vahlsten, O. Ruottinen, and M. Ojala. 2004. Noncoagulation of milk in Finnish Ayrshire and Holstein-Friesian cows and effect of herds on milk coagulation ability. J. Dairy Sci. $87: 3958-3966$.

Vallas, M., H. Bovenhuis, T. Kaart, K. Pärna, H. Kiiman, and E. Pärna. 2010. Genetic parameters for milk coagulation properties in Estonian Holstein cows. J. Dairy Sci. 93:3789-3796.

Varona, L., I. Mistzal, and J. K. Bertrand. 1999. Threshold-linear versus linear-linear analysis of birth weight and calving ease using an animal model. II. Comparison of models. J. Anim. Sci. 77:2003-2007.

Wright, S. 1922. Coefficients of inbreeding and relationship. Am. Nat. $56: 330-338$.

Zannoni, M., and S. Annibaldi. 1981. Standardisation of the renneting ability of milk by Formagraph. Sci. Tecn. Latt. Cas. 32:79-94. 